\title{
Pancreatic Pseudocyst with Gastric Outlet Obstruction: A Case Report and Literature Review
}

\author{
Syed Ibrahim Ghulam Rasul, Ikhwan Sani Mohamad, Zaidi Zakaria, \\ Syed Hassan Syed Aziz \\ Department of Surgery, Universiti Sains Malaysia
}

\begin{abstract}
Management of pancreatic pseudocyst is controversial.Surgical therapy has been clasically considered the treatment of choice for those pseudocysts. However, several studies have shown good results with percutaneous drainage. Percutaneous drainage can be performed easily, with minimal complication and may facilitate the resolution of a pseudocyst. We presented a case of a 20-year-old boy who sustained blunt abdominal trauma following motorvehicle accident. A large pancreatic pseudocyst developed within 3 weeks after the accident. Percutaneous drainage under ultrasound guidance was performed. The drainage flow decreased gradually until ceasing, and the pseudocyst disappeared.
\end{abstract}

\section{Introduction}

Pancreatic pseudocysts are localized fluid collections rich in amylase and other pancreatic enzymes and surrounded by a wall of fibrous tissue that is not lined by epithelium. The limited natural history data suggest that most pseudocysts usually resolve spontaneously and rarely produce complications. However, they can produce a wide range of clinical problems depending upon the location and extent of the fluid collection and the presence of infection. On the other hand, giant pancreatic pseudocysts $(>10 \mathrm{~cm})$ have a lower spontaneous resolution rate and are more difficult to treat than smaller pancreatic pseudocysts. We reported a 20 -year-old malay boy with a giant pancreatic pseudocyst post trauma that presented with gastric outlet obstruction symptom to the casualty.

\section{Case Report}

A 20-year-old man had an accident and presented to casualty with low Glasgow Coma Scale (GCS).He was ventilated in neurosurgical ward and treated as diffuse axonal injury Marshall grade 2. He was extubated at day two post trauma and discharged at day five post trauma. During his stay in the ward, he did complain of epigastric discomfort. He presented again after 2 weeks to casualty with complaint of worsening epigastric and left hypochondriac pain associated with vomiting. Vital monitoring at the time of admission showed pulse rate of $92 / \mathrm{min}$, a blood pressure of $110 / 70 \mathrm{~mm} \mathrm{Hg}$ and signs of dehydration. Physical examination revealed epigastric tenderness with a huge mass palpable at epigastric and left hypochondriac region. Laboratory investigation revealed serum amylase of $1530 \mathrm{IU} / \mathrm{L}$. Ultrasonography of the abdomen showed large pseudopancreatic cyst in the region of the tail of the pancreas. CT scan showed a pseudopancreatic cyst compressing the third part of the duodenum (Figure 1). The patient was subjected for percutaneous drainage under ultrasound guidance. The cyst was successfully drained within two weeks and the pigtail catheter was removed. Repeated ultrasound of the abdomen showed resolving cyst with normal pancreas. However the patient developed intraventricular sepsis secondary to the underlying head injury which warranted extraventricular drainage and antibiotic. He deteriorated and developed septic shock.He succumbed to death at third week of admission secondary to the sepsis.

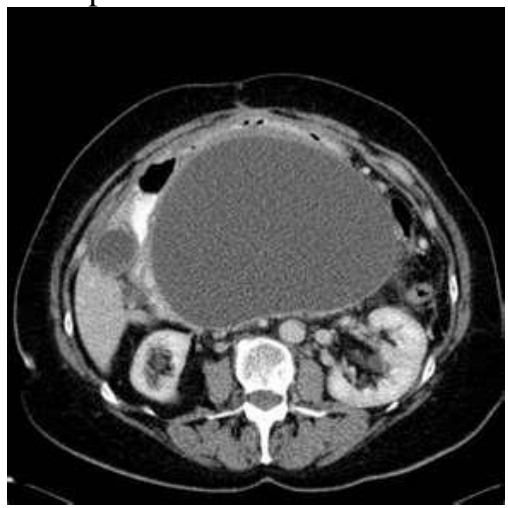

Figure 1 : Huge pseudopancreatic cyst arising from tail of pancreas 


\section{Discussion}

Pancreatic pseudocysts are localized fluid collections rich in amylase and other pancreatic enzymes and surrounded by a wall of fibrous tissue that is not lined by epithelium ${ }^{1}$. The limited natural history data suggest that most pseudocysts usually resolve spontaneously and rarely produce complications. However, they can produce a wide range of clinical problems depending upon the location and extent of the fluid collection and the presence of infection ${ }^{2}$

Pancreatic pseudocysts account for about two thirds of all pancreatic cystic lesions and develop in 10$20 \%$ of acute pancreatitis and $20-40 \%$ of patients with chronic pancreatitis. Ninety percent of pseudocysts are single. However, different authors quote an 11-18\% incidence of multiple pseudocysts in patients with acute and chronic pancreatitis ${ }^{3}$.

The pathogenesis of pseudocysts is believed to be due to disruption of the main pancreatic duct or peripheral ductules causing leakage and activation of pancreatic enzymes, which in turn leads to localized autodigestion and necrosis of pancreatic parenchyma. This evokes an inflammatory response with the formation of a distinct wall composed of granulation tissue and blood vessels that organizes with more connective tissue and fibrosis without an epithelial lining. It is most frequently located in the lesser peritoneal sac. Large pseudocysts can even extend into the paracolic gutters, pelvis, mediastinum, neck and scrotum. Pseudocysts associated with chronic pancreatitis are generally intrapancreatic 4.

Abdominal pain is present in $76-94 \%$ of cases of uncomplicated pseudocysts. Early satiety, nausea, vomiting and weight loss are other manifestations of this disease. Physical examination may reveal abdominal tenderness, epigastric fullness or a mass ${ }^{6}$.

A pancreatic pseudocyst may regress spontaneously; persist with or without symptoms or progress to produce complications ${ }^{5}$.

Obstruction of the pancreatic-biliary ducts and stomach is relatively common due to local compression. Duodenal compression causing gastric outlet obstruction is also reported in pseudocysts involving the head of the pancreas. Pseudocysts that compress the duodenum can cause nausea, vomiting and varying degrees of biliary obstruction ${ }^{7}$.

Life-threatening complications are reported in $10 \%$ of cases of pseudocysts and include hemorrhage due to rupture of pseudo-aneurysms in the wall of the pseudocyst, infection, pseudocyst-peritoneal fistula with resultant pancreatic ascites, gastric or rarely esophageal variceal bleed due to splenic or portal vein thrombosis, and erosion of the pseudocyst into the portal venous system and arteries such as splenic artery, gastroduodenal artery, pancreaticoduodenal artery, gastroepiploic and gastric arteries ${ }^{8}$.

Plain abdominal radiography may show a soft tissue mass displacing or compressing surrounding viscera such as stomach, duodenum or transverse colon. Pseudocysts on computed tomography appear as low attenuated homogeneous lesions within or adjacent to the pancreas along with the presence of a well defined, nonepithelial, fibrous wall which may enhance with the addition of contrast ${ }^{9}$.

Endoscopic retrograde cholangiopancreatography (ERCP) may reveal a partially or completely obstructed pancreatic duct due to either ductal fibrosis or extrinsic compression by the pseudocyst. Pancreatic ductal leakage may also be revealed by ERCP. Magnetic resonance imaging may be used as a noninvasive alternative to $\mathrm{ERCP}^{10}$.

The role of endoscopic ultrasonography has expanded in confirming the diagnosis, locating, determining the wall thickness and drainage of pseudocysts, which may appear as anechoic, fluid filled lesions within a welldefined wall adjacent to the gastrointestinal tract and pancreas. Further Color Doppler ultrasonography of the wall may reveal multiple, prominent vessels and para-gastric varices. Catheter probe endosonography can also be used to localize pseudocysts ${ }^{11}$

Radionuclide examination in the form of gallium-67 citrate and selenium-75 selenomethionine may detect a photon-deficient mass in proximity to the pancreas, indicating a pseudocyst. Angiography may reveal arterial pseudoaneurysms resulting from vessel erosion by a pancreatic pseudocyst. Fine needle aspiration cytology may differentiate between pseudocysts and cystic neoplasms of the pancreas ${ }^{12}$

Treatment of pseudocysts has traditionally been surgical with drainage of the pseudocyst internally into a hollow viscus. Jeddicka first described pseudocyst gastrostomy in 1921 with pseudocyst duodenostomy and pseudocyst jejunostomy being introduced later. Laparoscopic drainage is also done with success. External drainage using CT sonography guidance is successful in infected pseudocysts. Small intrapancreatic pseudocysts may be either resected or enucleated. Endoscopic drainage may be either transpapillary (via ERCP) or by transmural approach which depends upon the presence of a bulge into the stomach or duodenum. ${ }^{13}$

\section{Conclusion}

Pseudocysts are a well-known complication of pancreatitis. Gastric outlet obstruction due to duodenal compression is a very uncommon presentation. Drainage either surgically or endoscopically usually relieves the symptoms 


\section{References}

[1]. Kloppel, G. Pseudocysts and other non-neoplastic cysts of the pancreas. Semin Diagn Pathol, 2000. 17(1): p. 7-15.

[2]. Bernades P, Belghiti J, Place S, Knezevitch Y, Fekete F: Histoire naturelle des collections liquidiennes au cours de la pancréatite chroniques. Gastroenterol Clin Biol 1985; 9:2A.

[3]. Staub JL, Le Genissel H, Sarles H: Etude de la séméiologie et des résultats du traitement chirurgical de 103 cas de pancréatitis chroniques compliquées de kystes ou de pseudokystes. Gastroenterol Clin Biol 1981; 5:433-439.

[4]. Lasson A, Genell S, Nilsson A: Proteolytic activity in pancreatic pseudocyst fluid. Int J Pancreatol 1994; 15:201-208.

[5]. Richter HM: Natural history of pancreatic pseudocysts; in Howard J, et al (eds): Surgical Diseases of the Pancreas. Baltimore, Williams \& Wilkins, 1998, pp 417-421.

[6]. Pour PM, Thompson JS, Baxter BT: Pathology of pancreatic pseudocysts; in Bradley EL III (ed): Acute Pancreatitis. New York, Raven, 1994, pp 181-189.

[7]. Pitchumoni CS, Agarwal N. Pancreatic pseudocysts. When and how should drainage be performed? Gastroenterol Clin North Am $1999 ; 28: 615-39$

[8]. Aranha GV, Prinz RA, Esguerra AC, Greenlee HB. The nature and course of cystic pancreatic lesions diagnosed by ultrasound. Arch Surg 1983; 118:486-8.

[9]. Goulet RJ, Goodman J, Schaffer R, Dallemand S, Andersen DK. Multiple pancreatic pseudocyst disease. Ann Surg 1984; 199:613 .

[10]. Sahel J, Barthet MAPM: Pseudocysts; in Beger HG, Warshaw A, Carr-Locke DL, Russel RCG, Büchler M, Neoptolemos JP, Saar M (eds): The Pancreas. Boston, Blackwell Scientific, 1998, pp 748-753.

[11]. Brugge WR. Pancreatic Pseudocysts: Diagnoses, Imaging, and Treatment. Visible Human Journal of Endosonography. 2002; 1: 12.

[12]. Carr JA, Cho JS, Shepard AD, Nypaver TJ, Reddy DJ. Visceral pseudoaneurysms due to pancreatic pseudocysts: rare but lethal complications of pancreatitis. J Vasc Surg 2000; 32:722-30.

[13]. Boerma, D., et al., Internal drainage of infected pancreatic pseudocysts: safe or sorry? Dig Surg, 1999. 16(6): p. 501-5. 